\section{MAPPING AS A SPATIAL DATA SOURCE}

\section{ABSTRACT}

The basic database for a geographic information system (BD GIS) forms the core of a national spatial data infrastructure. Nowadays decisions are being made about the potential data sources for additional data updates and refinement of the BD GIS. Will the data from departmental or other information system administrators serve for this purpose?

This paper gives an answer as to whether it is advisable to use "geodetic mapping" (the results realized in the process of land consolidation) or "cadastral mapping" (the results realized in the process of the renewal of cadastral documentation by new mapping) for additional data updates. In our analysis we focus on the quality parameters at the individual data element level, namely the positional accuracy, attribute accuracy, logical consisten$c y$, and data resolution. The results of the analysis are compared with the contents of the Object Class Catalog of BD GIS (OCC), which describes the group of objects managed by BD GIS and defines the data collection methods, types of geometry and its properties.

Lubica HUDECOVA
Email: lubica.hudecova@stuba.sk
Research field: Cadastre of Real Estate,
Geodetic Applications in Land Consolidation,
Mapping and Acquisition of Topographic
Data, Basic National Map Series.
Address: Department of Mapping and Land
Consolidation,
Faculty of Civil Engineering,
Slovak University of Technology,
Radlinského 11, Bratislava 81368

\section{KEY WORDS}

- Basic database for a geographic information system,

- cadastre of real estate,

- land consolidation,

- spatial data source,

- large-scale mapping,

- renewal of cadastral documentation by new mapping.

\section{INTRODUCTION}

Spatial information is included in many information systems, including the Information System of Geodesy, Cartography and Cadastre (IS GCC). The Geodesy, Cartography and Cadastral Authority of the Slovak Republic has been made responsible for the reference spatial information guarantee by the National Concept of the eGovernment of the Slovak Republic.

BD GIS is a part of IS GCC. It creates a basic information infrastructure for the needs of stocktaking, collecting, sorting, data presentation, the analysis and synthesis of knowledge, and modelling a variety of solutions for state and public administration authorities, municipalities, businesses and the public [Act. No. 215/1995]. BD GIS contains spatial information about topographic objects and their basic characteristics with the degree of abstraction that is defined by the OCC [OCC, 2011].

The main method of data collection for BD GIS is a method involving digital photogrammetry and local on-the-ground examinations. The possibilities and alternatives for additional data updates are currently in the decision-making process.

Can the results of "geodetic mapping" or "cadastral mapping" be used for additional BD GIS updates? In this paper we will focus on an analysis of the content and quality of the spatial data sources obtained from large-scale mapping and on an evaluation of their efficiency.

\section{ASSESSMENT OF THE CONFORMITY OF THE CONTENT AND QUALITY OF SPATIAL DATA SOURCES}

Each data source reality model is simplified and does not provide a comprehensive representation of reality. If we want to use spatial sources several times, we have to be aware of their quality and analyze their diversity of content elements.

We focused on a trinity of spatial data sources, where the content of each one determines its purpose.

- BD GIS - spatial information about topographic objects and their principal characteristics;

- Geodetic mapping in the process of land consolidation - in addition to topographic features, it includes the thematic elements necessary for the projection and realisation of land consolidation;

- Cadastral mapping - considerably reduces topographic features; thematic elements strictly follow the needs of the real estate cadastre (cadastre). 


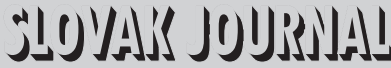 \\ 1)

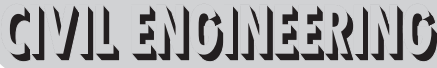

Vol. XXI, 2013, No. 1, $24-30$

We will observe some quantitative and descriptive quality parameters at the level of the individual data elements - positional accuracy, attribute and temporal accuracy, logical consistency, spatial and thematic data resolution.

\section{POSITIONAL ACCURACY AND DATA RESOLUTION}

The position of each spatial object has to be determined in a binding coordinate system.

\section{Geodetic mapping, cadastral mapping}

Geodetic mapping and cadastral mapping are related by the fact that their results are entered into a cadastre. The legislation (Act. No. 215/1995) determines the coordinate system, procedure, and methods of measurement and accuracy, which the licensed surveyor confirms by an authorized verification of the results.

The most frequently used measurement methods are geodetic; the position of objects is recorded in the current implementation of the horizontal datum of the Unified Trigonometric Cadastral Network (UTCN03). The heights are determined in the Baltic Vertical Datum (BVD) after adjustment. The accuracy of the resulting modell reflects the expected difference between the position of the object in the database and its "true" position. Its accuracy is determined by a precise determination of the coordinates "X", "Y" and "H" for the points of minor control and for the detailed points. The degree of accuracy is defined by the mean basic coordinate error " $\mathrm{m}_{\mathrm{xy}}$ ", the mean basic vertical error " $\mathrm{m}_{\mathrm{H}}$ ", and their permissible deviation (maximum). The following are the permissible " $u$ " deviations for the points of minor control and the detailed points:

Points of minor control:

$\mathrm{u}_{\mathrm{xy}}=0.04 \mathrm{~m}$
$\mathrm{u}_{\mathrm{H}}=0.06 \mathrm{~m}$

Detailed points:

$\mathrm{u}_{\mathrm{xy}}=0.08 \mathrm{~m}$

$\mathrm{u}_{\mathrm{H}}=0.12 \mathrm{~m}$

Spatial data resolution is closely related to the scale, which determines the final visualization of objects. The scale, which defines the level of abstraction for cadastral and geodetical mapping, corresponds to the purpose of the cadastre (large-scale mapping $-1: 1000$ or 1:2000). The detail of a land survey can be slightly adjusted according to, for example, the difficulty of the terrain.

Spatial resolution for large-scale mapping corresponds to the simplification of lengths to $10 \mathrm{~cm}$ and areas to $1 \mathrm{~m}^{2}$.

\section{BD GIS}

The position of BD GIS objects is recorded in the current implementation of the horizontal datum UTCN03. Spatial objects modelled for BD GIS are on a medium scale. Their positional accuracy is determined to $1 \mathrm{~m}$; the spatial resolution corresponds to the simplification of lengths to $5 \mathrm{~m}$ and areas to $15 \mathrm{~m}^{2}$, unless they are not defined in a different way in the OCC.

Table 1 shows an overview of the accuracy and resolution of the monitored data sources.

Tab. 1 Accuracy and resolution.

\begin{tabular}{|l|c|c|c|c|c|}
\hline & \multirow{2}{*}{$\begin{array}{c}\text { Geographical } \\
\text { Position }\end{array}$} & $\begin{array}{c}\text { Position } \\
\text { and Vertical } \\
\text { Accuracy }\end{array}$ & Scale & \multicolumn{2}{|c|}{$\begin{array}{c}\text { Spatial Resolution } \\
\text { Ability }\end{array}$} \\
\cline { 5 - 6 } & & Line & Area \\
\hline $\begin{array}{l}\text { Geodetic } \\
\text { Mapping }\end{array}$ & $\begin{array}{c}\text { UTCN03 } \\
\text { BVD }\end{array}$ & $\begin{array}{c}0.08 \mathrm{~m} \\
0.12 \mathrm{~m}\end{array}$ & $1: 2000$ & $0.1 \mathrm{~m}$ & $1 \mathrm{~m}^{2}$ \\
\hline $\begin{array}{l}\text { Cadastral } \\
\text { Mapping }\end{array}$ & UTCN03 & $\begin{array}{c}0.08 \mathrm{~m} \\
-\end{array}$ & $1: 1000$ & $0.1 \mathrm{~m}$ & $1 \mathrm{~m}^{2}$ \\
\hline BD GIS & UTCN03 & $\begin{array}{c}1 \mathrm{~m} \\
1.7 \mathrm{~m}\end{array}$ & $1: 10000$ & $5 \mathrm{~m}$ & $15 \mathrm{~m}^{2}$ \\
\hline
\end{tabular}

\section{LOGICAL CONSISTENCY}

The logical consistency of the data reflects whether a graphic representation of the objects has no gaps or overlaps. The division of the space, contents and features of objects are based on their purpose. We distinguish object features that require measurement (position, distance) and features based on non-geometric information (topology). The topology expresses such an interconnection (the linkage of rivers and lakes), orientation (direction of a flow) and adjacency (between plots).

\section{Geodetic mapping}

A particular area is measured in order to avoid gaps and holes. All the planimetric and altimetric components in a land consolidation perimeter are measured; if necessary for this purpose, this should also be done outside the perimeter (e.g., road connections, canals and environmental equipment). Some places can be represented more than once, namely, in the case of above-the-ground and underground facilities (cellars in vineyards, piping, landscape created elements, bridges).

Geodetic mapping in the land consolidation process includes topographic and thematic elements. The topographic components of the measurements are:

- Waters,

- Territorial boundaries (cadastral districts, built-up areas, geodetic mapping perimeters),

- Road and rail communications,

- Settlements (residential, administrative, manufacturing and other facilities),

- Technical facilities (dams, bridges, energy networks),

- Selected elements of vegetation and land cover (forests and permanent crops, shrubs, grassland vegetation),

- Altimetric elements. 
Thematic features are necessary:

- for making the local Territorial System of Ecological Stability and general regulations functionally organizing a territory in a land consolidation perimeter (groups of trees and shrubs, solitaires, species, height and thickness of trees, etc.) (Muchová, 2009);

- for designing common facilities and arrangements and the design of new plots (ecological and landscape arrangements, the direction of vineyard rows and fruit trees, monuments, crosses, etc.) (Muchová, 2009);

- for cadastre (points of minor control, boundaries of territorial units, boundaries of ownership and rights to use, nature of land use and type of lot exploitation) (Hudecová, 2010).

\section{Cadastral mapping}

The area is always measured without gaps. Cadastral mapping is based on the subject of the registration in a cadastre (Act. No. 162/1995) and on the contents of the Basic Large-Scale Map of the Slovak Republic. The subject of the survey significantly reduces the topographic elements because of a preference for boundaries defined by rights to real estate.

\section{BD GIS}

The detail of BD GIS is determined by the OCC (OCC, 2011). The OCC describes objects, their attributes and data collection methods. It is standardized by the international standard of DIGEST (Digital Geographic Information Exchange Standard). Each object has its own code under which the object belongs to the category and subcategory according to FACC (Feature Attribute Coding Catalogue), Table 2.

BD GIS tends to cover $100 \%$, which means that each position can be represented only once. This rule has proved unrealistic in practice; therefore, some exceptions are allowed (e.g., overlays of bridge construction).

Table 3 shows an overview of the dimensions of the geometric modelling, covering and extent of the territory of interest, and the content and properties of objects.
Tab. 2 The list of categories of objects according to DIGEST.

\begin{tabular}{|c|l|}
\hline \multicolumn{2}{l}{ DIGEST } \\
FACC - Feature Attribute Coding Catalogue \\
\hline Category code & Category name \\
\hline A & Anthropogenic elements - culture \\
\hline B & Waters \\
\hline C & Altimetry \\
\hline D & Surface \\
\hline E & Vegetation \\
\hline F & Borders \\
\hline G & Aeronautical navigation information \\
\hline I & Cadastre or real estate \\
\hline O & Roads \\
\hline S & Special use \\
\hline Z & General \\
\hline
\end{tabular}

\section{ATTRIBUTE AND TEMPORAL ACCURACY}

Attributes describe spatial objects. Attribute values not only need to be measured, but also sometimes can be traced or visually detected. Attributes that do not contain information about a location and spatial relations ("non-spatial") say more about the quality of a spatial object. It is possible to monitor their completeness, detail, accuracy and topicality. Temporal accuracy expresses the date of the determination, measurement or tracing of an object (the state of the knowledge about an object), the date of its creation and determining changes in the object's status (the state of knowledge about changes in objects), which can be used to monitor their life cycle.

Tab. 3 Logical consistency.

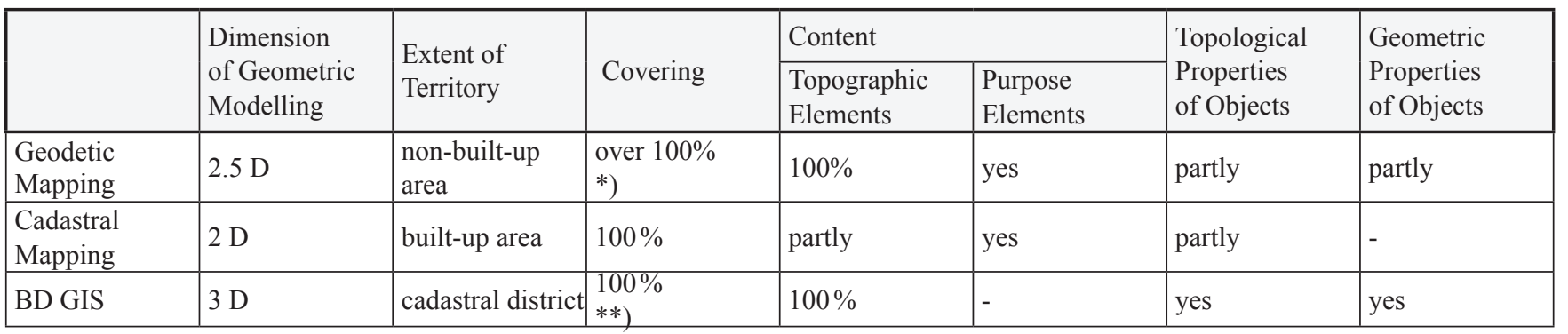

*) also overhead and underground objects

**) no underground objects; exceptions are allowed among overhead objects (such as bridges) 


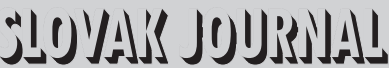 \\ 1) 5

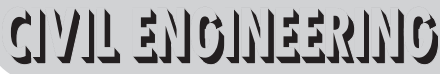

Vol. XXI, 2013, No. 1, $24-30$

Tab. 4 Attribute accuracy and temporal accuracy .

\begin{tabular}{|c|c|c|c|c|}
\hline & \multirow[b]{2}{*}{ Attribute Accuracy } & \multicolumn{2}{|c|}{ Temporal accuracy } & \multirow[b]{2}{*}{ Frequency of Updates } \\
\hline & & $\begin{array}{l}\text { State of Knowledge } \\
\text { about an Object }\end{array}$ & $\begin{array}{l}\text { State of Knowledge } \\
\text { about Change in an Object }\end{array}$ & \\
\hline $\begin{array}{l}\text { Geodetic } \\
\text { mapping }\end{array}$ & $\begin{array}{l}\text { Land consolidation }+ \\
\text { Cadastre of real estate }\end{array}$ & $\begin{array}{l}\text { completion of detailed survey } \\
\text { phase }\end{array}$ & no & cca 100 years \\
\hline $\begin{array}{l}\text { Cadastral } \\
\text { mapping }\end{array}$ & Cadastre of real estate & declaration of validity & no & cca 100 years \\
\hline BD GIS & $\mathrm{OCC}$ & $\begin{array}{l}\text { aerial survey photograph, local } \\
\text { on-the-ground examination }\end{array}$ & yes & 3 years \\
\hline
\end{tabular}

\section{Geodetic mapping}

Attributes are determined, measured on a terrain, or traced from administrators. Some attributes may be presented graphically in a field survey document (thickness, height and type of tree, direction of vineyard rows). Coded data collection can be used. The range of attributes follows the needs of a land consolidation project and cadastre (age of vineyards, flammability or inflammability of contructions, illegality of structures, etc.). The attribute of "the state of knowledge about an object" expresses the date of completion of a detailed survey phase.

\section{Cadastral mapping}

Attributes are determined or measured on a terrain or traced from administrators. They are represented on a field sketch and in the record of mapping elementary proceedings. The range of attributes only follows the needs of a cadastre (fence type, type of marking of a control station, flammability or inflammability of constructions, character of a boundary - indistinct, disputable, moving, invisible, etc.). The attribute of "the state of knowledge about an object" expresses the date of the declaration of the validity of the renewed cadastral documentation (declaration of validity).

\section{BD GIS}

Each class of objects has general and specific attributes. General attributes are defined as the date of creation, the date and state of knowledge about an object, the origin of the data, its reliability, and the horizontal and vertical accuracy. Each object contains a detailed description of the data collection and compulsory attributes of the object.

Table 4 shows an overview of attribute and temporal accuracy as well as the frequency of updates.

\section{ANALYSIS OF THE THEMATIC RESOLUTION OF SELECTED OBJECTS}

The analysis was focused on "plant and land cover" objects. Table 5 compares the elements of "vegetation and land cover" in geodetic and cadastral mapping, and representation of 3D "Vegetation" objects in BD GIS [OCC, 2011].

\section{BD GIS}

The areas in BD GIS are evaluated and represented according to the rules set out in the OCC, starting from the aerial survey photographs and the results of the local on-the-ground examination. Vegetation and land cover objects (vegetation category) are processed by view, while areas of less than $300 \mathrm{~m}^{2}$, respectively 400 $\mathrm{m}^{2}$, are included in the surrounding area.

\section{Geodetic mapping}

In geodetic mapping the actual status of the land use, nature, and types of lot exploitation is measured (elements of vegetation and land cover). It is the basis for designing a new arrangement of a territory. An "expert commission" also takes part in the design. Detected demarcations are reconsidered by the commission, and if necessary, the commission can decide to change them. The commission has the authority to redefine the delimitation of any agricultural land and forested land (Figure 1), decide on the nature of any land use changes (arable land, permanent grass growth, orchards and gardens) and determine new boundaries of special cultures (hop gardens, vineyards). A "modified" demarcation of the nature of land

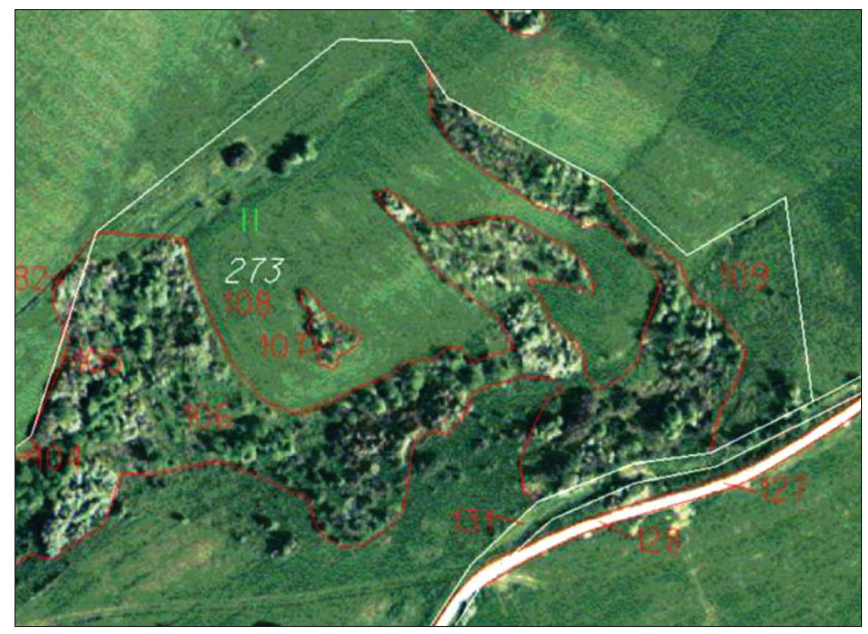

Fig. 1 Overview of the modified demarcation of permanent grass growth.
(C) Progres CAD Engineering) 
Tab. 5 Vegetation and land cover elements for geodetic mapping, cadastral mapping and BD GIS objects - "vegetation" category.

\begin{tabular}{|c|c|c|c|}
\hline \multicolumn{2}{|r|}{ Geodetic mapping } & Cadastral & OCC \\
\hline 冚 & $\begin{array}{l}\text { Arable land } \\
\text { Permanent grass growth, meadow -continuous vegetation } \\
\text { intended to be cut } \\
\text { Vineyards } \\
\text { Hop gardens } \\
\text { Gardens } \\
\text { Orchards }\end{array}$ & $\begin{array}{l}\text { Arable land } \\
\text { Permanent grass } \\
\text { growth }\end{array}$ & \multirow{7}{*}{$\begin{array}{l}\text { Arable land, area } \geq 400 \mathrm{~m}^{2} \text {, fertile or fertilized } \\
\text { cultivated land suitable for agricultural purposes } \\
\text { Meadow, area } \geq 300 \mathrm{~m}^{2} \text { covered with continu- } \\
\text { ous grassland, intended for mowing, pasturage } \\
\text { or other purposes } \\
\text { Vineyards, area } \geq 300 \mathrm{~m}^{2}, \text { fenced or not } \\
\text { Hop gardens, area } \geq 400 \mathrm{~m}^{2} \\
\text { Orchards, gardens, area } \geq 300 \mathrm{~m}^{2} \text {, fenced or } \\
\text { not, for the cultivation of fruit trees and other } \\
\text { useful plants, gardens, gardening colonies } \\
\text { Forest, area } \geq 400 \mathrm{~m}^{2} \text { covered with forested } \\
\text { trees, wide }>15 \mathrm{meters,} \mathrm{tree} \mathrm{cover}>20 \% \text {. } \\
\text { Potential tree height of the area }>5 \mathrm{~m} \\
\text { Hedgerow, alley }- \text { line of shrubs arranged into } \\
\text { a narrow strip Grassy and shrubby vegetation, } \\
\text { area } \geq 400 \mathrm{~m} \mathrm{~m}^{2} \text { covered with continuous grassy } \\
\text { vegetation with individual or grouped bushes } \\
\text { Useful greenery, area } \geq 300 \text { m², grass, shrubs, } \\
\text { trees may include alleys in parks, cemeteries, } \\
\text { settlements } \\
\text { Arboretum, special-purpose equipment for the } \\
\text { production of domestic and exotic plants for } \\
\text { study, cultivation and other purposes }\end{array}$} \\
\hline \multirow{6}{*}{$\frac{\tilde{a}}{\frac{0}{0}}$} & $\begin{array}{l}\text { Utility forest, protective forest, forest for special purpose, } \\
\text { forest at extremely unfavorable location, the area above } \\
\text { the upper forest line, seed orchards and plantations, glades, } \\
\text { vacant lots }\end{array}$ & \multirow{6}{*}{$\begin{array}{l}\text { Hop gardens } \\
\text { Gardens } \\
\text { Orchards } \\
\text { Forest lots }\end{array}$} & \\
\hline & Tree, group of trees & & \\
\hline & $\begin{array}{l}\text { Shrubs, shrub-dominated and tree-dominated thickets. } \\
\text { Riparian vegetation with a width }>10 \mathrm{~m}\end{array}$ & & \\
\hline & $\begin{array}{l}\text { Alley - a narrow strip of trees, hedgerows, strip of } \\
\text { shrubs of a width to } 10 \mathrm{~m} \text { and a length of over } 15 \mathrm{~m} \text { with } \\
\text { a maximum } 10 \mathrm{~m} \text { pitch }\end{array}$ & & \\
\hline & $\begin{array}{l}\text { Low shrubby vegetation, continuous grassy vegetation with } \\
\text { individual or grouped bushes. }\end{array}$ & & \\
\hline & $\begin{array}{l}\text { Forest gap, with a width }>5 \mathrm{~m} \text { and length }>15 \mathrm{~m} \text {; transport, } \\
\text { handling breaks in the forests, breaks over and under } \\
\text { networks }\end{array}$ & & \\
\hline
\end{tabular}

*) boundaries are determined in accordance with an agreement or according to decision of the agricultural and forest land protection authority

uses can also be binding for a cadastre (Act. No. 162/1995). New road networks and landscape elments are designed only after the work of the commission is finished.

When making its decision, the commission takes into account:

- the rules of land delimitataion (morphometric relief parameters, bioclimatic conditions, estimated pedologicalecological units, etc.);

- the protective and ecological functions of the area, in order to protect the soil, water, and population and to improve its ecological stability (Muchová, 2009);

- the size and shape of the land units (areas with a little screage are allocated to the predominant nature of the land use);

- the status registered in the cadastre (nature of land use and types of lot exploitation);

- the status displayed on the forest maps;

- the presence of planimetry elements (surface markers of engineering networks, course of pipelines, archeological sites, etc.);

- boundaries of built-up areas and cadastral districts.
Figure 2 contains an overview of the vegetation and land cover processed in a land consolidation project in the Lomnička cadastral district. In part a) the figure actually represents the detected and measured elements of the vegetation and land cover; in part b) the figure represents the elements of vegetation and land cover adjusted according to a decision of the expert commission, i.e. the nature of the land use binding on the cadastre. They contain visible differences. What is important is that none of these spatial data sources are suitable for additional updates of the BD GIS (for "Vegetation" objects). Figure 2, part a), contains demarcations that reflect the measured elements which will be changed during the design of a new territory. Figure 2, part b), contains demarcations of the objects that are modified by the commission, which correspond to the content of the cadastre but do not correspond to the content of the BD GIS.

\section{Cadastral mapping}

In cadastral mapping the nature of a land use registered in a cadastre before mapping remains valid even after mapping. Changes in the nature of a land use can be done under the authority of the state administration authorities responsible for agricultural 


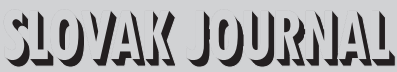 \\ 1) 5

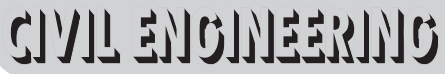

Vol. XXI, 2013, No. 1, $24-30$

\section{Lomnička land consolidation project area of project: $9564870 \mathrm{~m} 2$}

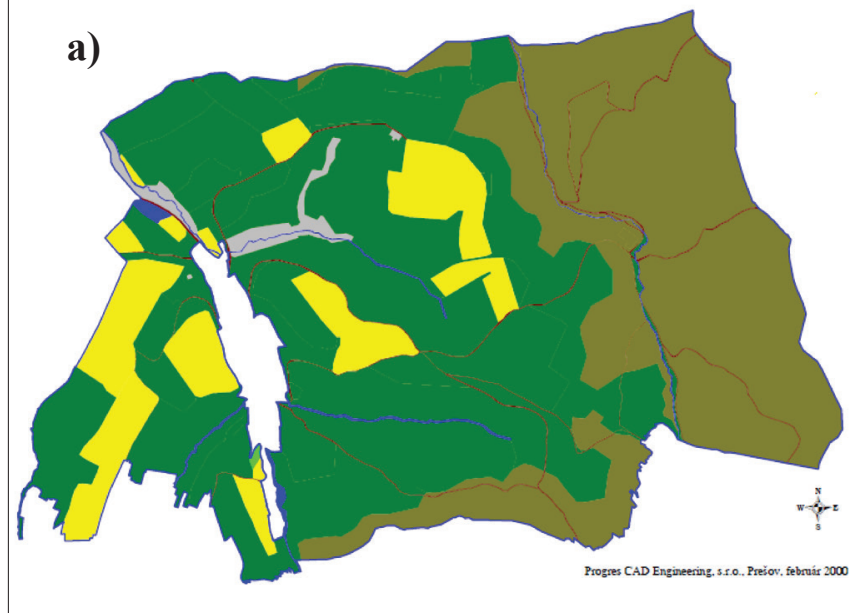

Fig. 2 a) detected and measured elements of vegetation and land cover; b) nature of land uses binding on the cadastre.

(C) Progres CAD Engineering). and forested land and for construction activities (except in certain cases where the document is not required).

Cadastral mapping results are not suitable for additional updates of the BD GIS (for "Vegetation" objects). The reason is that demarcations of objects are linked to the legally stated natures of land use and types of lot exploitation (Act. No. 162/1995), which are inconsistent with the content of BD GIS.

\section{CONCLUSIONS}

Table 6 contains categories of BD GIS objects and an evaluation of the possibilities of additional updates using large-scale spatial sources from geodetic and cadastral mapping. The bottom line in the table contains the estimated number of BD GIS objects, which can be updated by the use of the data sources compared.

We note that the large-scale data sources compared from the geodetic and cadastral mapping are useful for additional updating of the BD GIS (Tables 1, 3, 4) in terms of positional accuracy, logical consistency, and attribute and temporal accuracy. The results of a thematic resolution analysis, which is focused on "vegetation and land cover" objects, have defined the range of the applicability of the monitored databases (Figures 1, 2, Table 5) (Hudecová, 2012).

The effectiveness of the utilization of "large scale" mapping for additional updating of the BD GIS will be shown in the future. A complex analysis of the content elements will define the scope of the objects which can be used (Table 6). The idea of multiple use and the integration of data and information collected in different information systems constantly pushes us forward and makes us look for new approaches and solutions.

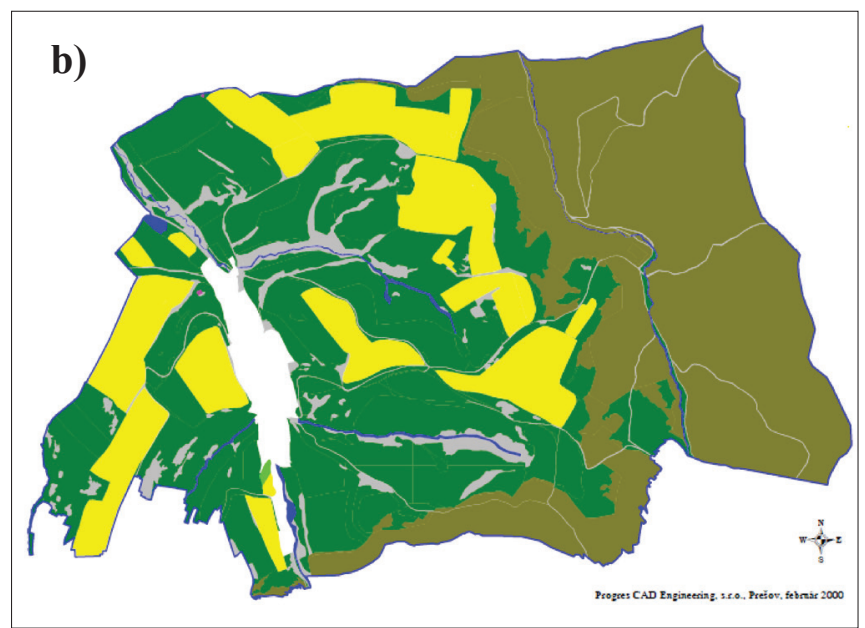

Tab. 6 Estimation of the applicability of geodetic mapping and cadastral mapping for BD GIS.

\begin{tabular}{|l|c|c|}
\hline \multirow{2}{*}{$\begin{array}{l}\text { BD GIS, Categories } \\
\text { According to ACC }\end{array}$} & \multicolumn{2}{|c|}{ Applicability } \\
\cline { 2 - 3 } & Geodetic Mapping & Cadastral Mapping \\
\hline $\begin{array}{l}\text { A - Anthropogenic } \\
\text { elements - culture }\end{array}$ & $100 \%$ & partly*) \\
\hline B - Waters & $100 \%$ & partly**) \\
\hline C - Altimetry & $100 \%$ & - \\
\hline D - Surface & $100 \%$ & - \\
\hline E - Vegetation & $0 \%$ & $0 \%$ \\
\hline F .. Z & - & - \\
\hline Estimate of applicability & $\mathbf{5 5 \%}$ & $\mathbf{1 1 \%}$ \\
\hline
\end{tabular}

*) buildings

**) watercourses, water surfaces, springs, wells 


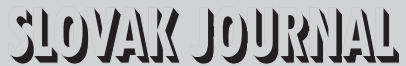 \\ 1) $s^{3}$

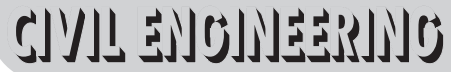

Vol. XXI, 2013, No. 1, $24-30$

\section{REFERENCES}

Hudecová, L. (2010) Prínos pozemkových úprav pre kataster nehnutel'ností (Land Consolidation Effect for Real Estate Register), In: 10-th international conference on Real Estate, Karlove Vary, CR. ISBN 978-80-02-02257-2 (in Slovak).

Hudecová, L. - Repáň, P. - Zámečník, P. (2012) Viacnásobné využívanie priestorových údajových zdrojov (Multiple Use of a Spatial Data Source), In: Geodesy, Cartography and Geographic Information Systems, Tatranská Lomnica, ISBN 97880-553-1173-9 (in Slovak).
Object Class Catalog of Basic Database for Geographic Information System (working version 2011), GCCA SR, Bratislava.

Muchová, Z. et al. (2009) Metodické štandardy projektovania pozemkových úprav (Methodological standards for land consolidation design), MP SR, SPU v Nitre, ISBN 978-8-552-0267-9.

Act. No. 162/1995, Cadastre of real estate and registration of proprietary interests and other rights to real estate, as amended.

Act. No. 215/1995, Geodesy and cartography, as amended. 